\title{
A renaissance for mining research in South Africa?
}

\author{
D. Vogt CSIR Centre for Mining Innovation, South Africa
}

\section{Abstract}

Mining research in South Africa dates back to the early days of the Witwatersrand gold fields: research into seismicity celebrated its centenary in South Africa in 2010, and advances in the understanding of seismicity and rock mechanics allowed the gold mines to continue operating during the 1960 s.

With few exceptions, research in South Africa was driven by the industry, and was largely undertaken at the industry's own research facility, the Chamber of Mines Research Organisation, or COMRO.

In the early 1990s, several factors combined to lead the industry to abandon COMRO: the low gold price; the establishment of a safety levy to fund the newly created statutory Safety in Mines Research Advisory Committee; and the emergence of South Africa from isolation which allowed mining companies to invest in lower cost deposits in other countries. A period of decline in mining research followed.

After 20 years of neglect, the industry and government are recognising the role that research played in the past, and are acknowledging the need for continued impact to ensure that future mines are able to access new technology. They are also recognising the role played by the highly skilled individuals produced in research environments.

The CSIR is working with key stakeholders to form the nucleus of a revived research capability in the country through the establishment of a Centre of Excellence for safety and health; and through its internal mining Research Impact Area. Anglogold Ashanti and its Technology Innovation Consortium are also increasing interest in research. The signs are promising that South Africa is starting to support its researchers again in the way that other major mining countries have over the last decade.

\section{Introduction}

This paper discusses the status of pre-competitive mining research in South Africa, largely as undertaken by the CSIR and COMRO before it. The paper follows the history of mining research through to the current crisis of capacity, and looks at future opportunities.

Mining research has been conducted in South Africa since almost the earliest days of the industry. By the middle of the 20th century, that work was being almost exclusively conducted by the industry itself, and from the 1960s it occurred largely through COMRO. In the late 1980s the industry found itself under pressure to cut costs, and closed much of its research capability, leading to a 20 year decline in mining research in South Africa.

In the last few years, interest in research has been rekindled by the challenges posed by safety, and by the recognition that mining methods have to change. This paper examines the history of research, its current state, and proposals now on the table to revitalise the research landscape. The discussion in this paper is limited to the activity of mining, and does not cover the related fields of exploration or minerals processing. For historical reasons, those activities fall under separate science councils in South Africa: the Council for Geoscience and Mintek respectively. At the time of writing, R 1 is approximately equal to US\$ 7 and A\$ 7. In round figures, one-person-year of researcher time costs $\mathrm{R} 1$ million. 


\section{$2 \quad$ History of mining research in South Africa}

There is probably no better summary of the history of mining research in South Africa up until 1994, than pages 92 and 93 of the Leon Commission Report (Leon et al., 1995). Much of what follows is from that source.

\section{1 The birth and growth of COMRO}

The South African gold mining industry commenced some research activities in the early part of the 20th century. Initially the work was entirely restricted to health or health related matters (effect of dust, heat physiology) and to issues such as combating fungi in underground timber, vegetation of dumps and so on. Much of this work was carried out by a relatively small staff employed by the Chamber of Mines (COM). In the first half of the century, issues directly related to mining, such as the rockburst problem, were tackled on an ad-hoc basis mostly by mining engineers, employed in various capacities by the mining companies. The realisation came in the early 1950s that rockbursts and similar complex problems could not be solved by the uncoordinated spontaneous efforts of individuals or even by individual companies. Thus, in 1953, the COM was asked to initiate and coordinate a major research effort to tackle the rockburst problem (Leon et al., 1995).

The CSIR had established a rock mechanics capability in the late 1940s in the National Mechanical Engineering Research Institute in Pretoria, under the leadership of A.J.A. Roux and H-G. Denkhaus. This rock mechanics group prospered under E. Hoek and Z.T. Bieniawski in the late 1960s and 1970s and beyond (Stacey et al., 2008). In the 1950s, the Rand Mines Limited Corner House Laboratories began operating, focussing on rockburst and heat stress research, and later become the genesis of COMRO (Stacey et al., 2008).

The COM commissioned the CSIR to conduct investigations around the rockburst problem, but the industry soon became disillusioned with the progress of the research, finding the personnel at CSIR were too remote from the mines (Leon et al., 1995). In about 1960, the industry approached Sir Basil Schonland, a leading South African scientist and science adviser, for advice on its research policy (Pogue, 2006). He recommended that the gold industry had major technological problems, so it should embark on its own research programme, and that the COM should develop science management capacity. The COM proceeded to appoint a research adviser, consolidate existing COM research laboratories and employ several young researchers of international calibre. It followed shortly afterwards with the formation of COMRO (Leon et al., 1995).

At about the same time, there was a major disaster at Coalbrook Colliery in 1960, in which a pillar run led to the loss of 437 lives. It was decided by industry and government to introduce a small safety research levy on coal production, and to use the funds to undertake research. The Coal Mining Research Controlling Council (CMRCC), with representatives from both industry and government, was established to oversee the research. At first, CMRCC research was carried by the Fuel Research Institute, the CSIR, and the Council itself. In 1966, the Council's staff members were incorporated into COMRO (Leon et al., 1995).

In the early 1970s COMRO's research effort received a major boost with the sudden and major increase in the price of gold caused by the departure of the United States from the gold standard (Pogue, 2006). The profitability of mining companies increased, and it became economically feasible to develop the technological underpinning for the future of the industry. In 1974, the gold industry approved a R 100 million (at the time) ten year capital Research and Development (R\&D) plan to focus on four critical problems: rockbursts; cooling; mechanisation of stoping and human resource problems. This very large investment allowed COMRO to triple its activities (Leon et al., 1995).

\section{2 The death of COMRO}

From the early 1980s, the price of gold was declining (Figure 1), the rand was weakening against the dollar, the rate of research progress was slowing and there were differences of opinion about research directions, 
so by the late 1980 s mining companies had lost their enthusiasm for collective research. At about the same time, the Government Mining Engineer (GME) - today the Chief Inspector of Mines - faced with a declining safety situation and industry reluctance to undertake research, made it clear that he wished to extend the CMRCC approach from coal to all safety research.

\section{Gold price, USD per ounce (London pm fix)}

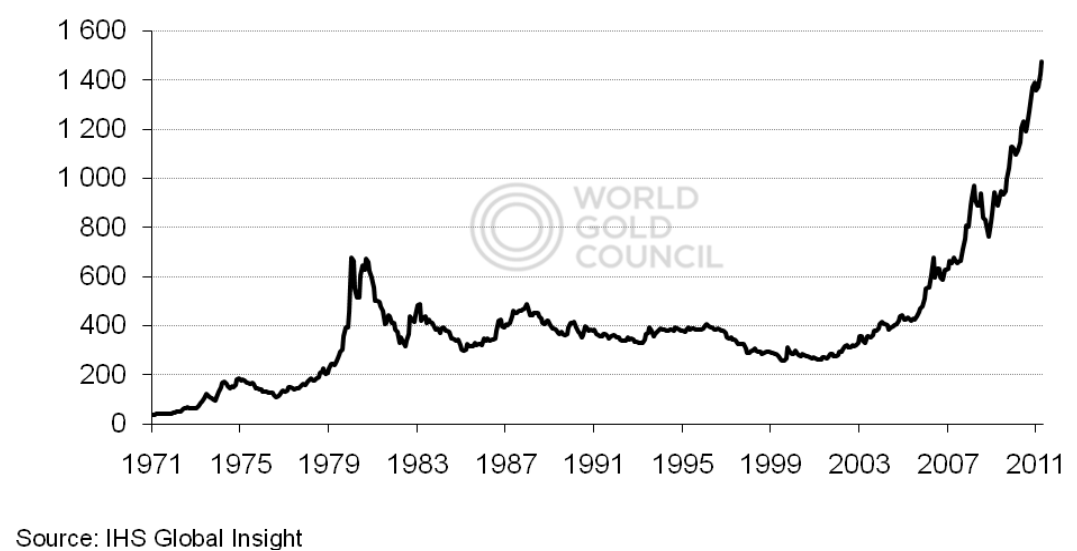

Figure 1 Gold price history in US\$ (World Gold Council, 2011)

In 1988 the mining industry warned that it could no longer afford such a large research organisation. By the end of 1992, COMRO ceased to exist, and its personnel and resources were merged with the CSIR, where, in 1993, they became the Mining Technology division known as Miningtek (Stacey et al., 2008).

At about the same time, the GME drafted legislation that created a safety research account, largely funded by a levy paid by mines, determined by their safety performance. This funding allowed for the creation of the Safety in Mines Research Advisory Committee, or SIMRAC, in 1992.

\section{3 The Leon Commission}

In 1993, industry and the government bowed to pressure from the Nation Union of Mineworkers (Looch, 2009) and a commission of inquiry was set up to investigate the poor health and safety record of the South African industry. The commission was chaired by the Honourable R.N. Leon, assisted by Professor A.W. Davies, Professor J.C.A. Davies and Professor M.D.G. Salamòn. It was the first commission to consider mine health and safety for more than 30 years, and led to the rewriting of the Mine Health and Safety Act, as well as to large scale changes in the conduct of government sponsored R\&D into mine health and safety.

The Leon Commission reviewed SIMRAC shortly after its creation and carried out a number of changes in the way it operated: the management committee had consisted only of state and industry representatives - the Leon Commission established the tripartite governance that endures today. Originally SIMRAC only concerned itself with safety - the Commission recommended that health problems also be addressed and that the basis for the levy imposed on mines is extended from safety performance to safety and health performance.

The Leon Commission also made recommendations about management of research. It acknowledged a need for clear policy with regard to research objectives, targets and priorities, and recommended that this policy be determined by SIMRAC at a high level, using tripartite principles.

It also identified a second technical level of decision making:

"No one questions that the management of a mine requires specialist knowledge and considerable experience. Surprisingly, it is often overlooked that the management of research is an equally specialised occupation and demands considerable experience." (Leon et al., 1995). 
The Commission noted that the technical committees at the time were largely composed of mining and other engineers with mine management experience, and stated that "it is unfair to expect such groups to control and guide to the best advantage research conducted by outside bodies whose interests do not entirely coincide with those of the three parties involved in mining." It therefore recommended that research advisors be appointed to assist in administration of the programme, and to advise SIMRAC and its sub-committees on research issues.

The Commission also made strong recommendations on programme management, to ensure that research programmes are needs driven, with specific goals, and effective in achieving their goals. It is interesting that the last paragraph in that section comments on rockburst research, specifically on the seismic approach being followed, "the primary need at this stage is to relate the seismic observations to mining layouts and to regional support systems. Progress in this field is urgently needed, while the current project probably becomes relevant only when the interrelationship between mining and seismicity has been established." This statement is as true today as it was in 1995.

Finally, the Commission recommended that an independent review panel be established to ensure that SIMRAC research did not become "superficial, misdirected and amateurish". The panel would consist of three to five eminent researchers, would be appointed for at least three years to ensure continuity, and would review research objectives, priorities, the annual research programme and progress.

\section{4 The Mine Health and Safety Council after the Leon Commission}

Since 1993, SIMRAC has been the main sponsor of health and safety research in South Africa. Following the Leon Commission, the Mine Health and Safety Council (MHSC) was established, with SIMRAC as a sub-committee. Until 2003, SIMRAC issued its own annual reports; from 2003, its activities are reported in the MHSC annual reports.

The MHSC and SIMRAC are both run on tripartite principles: there is equal representation of labour, the state and industry. The tripartite system was meant to give labour a voice in directing research, at a time when the industry appeared to dominate decision making (Leon et al., 1995). In practice, industry views still appear to dominate the agenda of the MSHC, although latterly the state has started to make its voice heard.

The MHSC budget is illustrated in Figure 2. From the figure, a number of features are clear:

- Expenditure on research has been steadily falling in real terms almost since the formation of SIMRAC in 1993.

- The administrative burden has been slowly increasing. This reflects a change in the MHSC mandate: when SIMRAC was formed it only undertook research. As it became part of the MSHC other activities such as promotion of health and safety came to consume a large part of the budget. In 2010, less than half of the total income was directed towards mining research.

- Recently, there has been a large variation in the research budget from year to year. It has not been possible for research providers to rely on MHSC funding for a period of longer than one year, which has had implications on investments in equipment and in people. The system makes it nearly impossible for a research provider to fund a $\mathrm{PhD}$ student, for example, as there is no guarantee that funding will be secure for the minimum of three years required. In about 2003, the MHSC embarked on a new policy of large, long-term projects in some of its key research areas, including silicosis elimination and rockburst research. While the policy allowed for the creation of large, multi-year programmes, funding was not guaranteed, and had to be approved every year. Almost without exception the approval process caused delays to projects. 


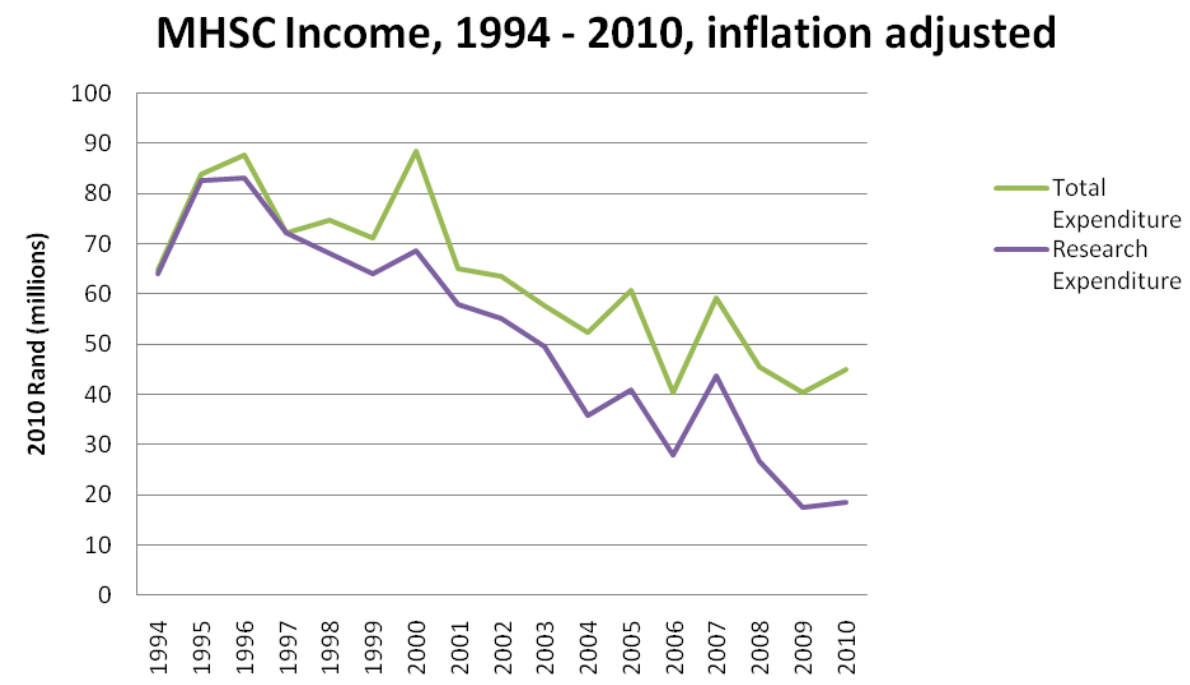

Figure 2 MHSC spending on research compared to total budget (derived from annual reports of SIMRAC and the MHSC from 1993 to 2010. The 1999 figure is pro-rata, correcting for a change in financial year. Years prior to 1999 represent the finances of the year ending 31 December of the previous year. Inflation has been accounted for using the June to June inflation in the Consumer Price Index, as published by Statistics South Africa, with 2010 as the base year. Expenditure in 2002 and 2003 is an estimate from Rymon-Lipinski and Adams (2003) and is planned cost rather than actual cost)

In Figure 3, the relative funding varying over time for the various MHSC priorities identified in 2003 is plotted:

- There is high year-to-year variation in particular disciplines. This mirrors the overall high year-toyear variation in total funding, and exacerbates the problems mentioned previously in terms of investing in people or long-term studies.

- Special projects take up $15-30 \%$ of the research budget.

- Research into rockbursts has ceased, although rockbursts still account for between 20 and $30 \%$ of all fatalities. 


\section{Change in MHSC project distribution with time}

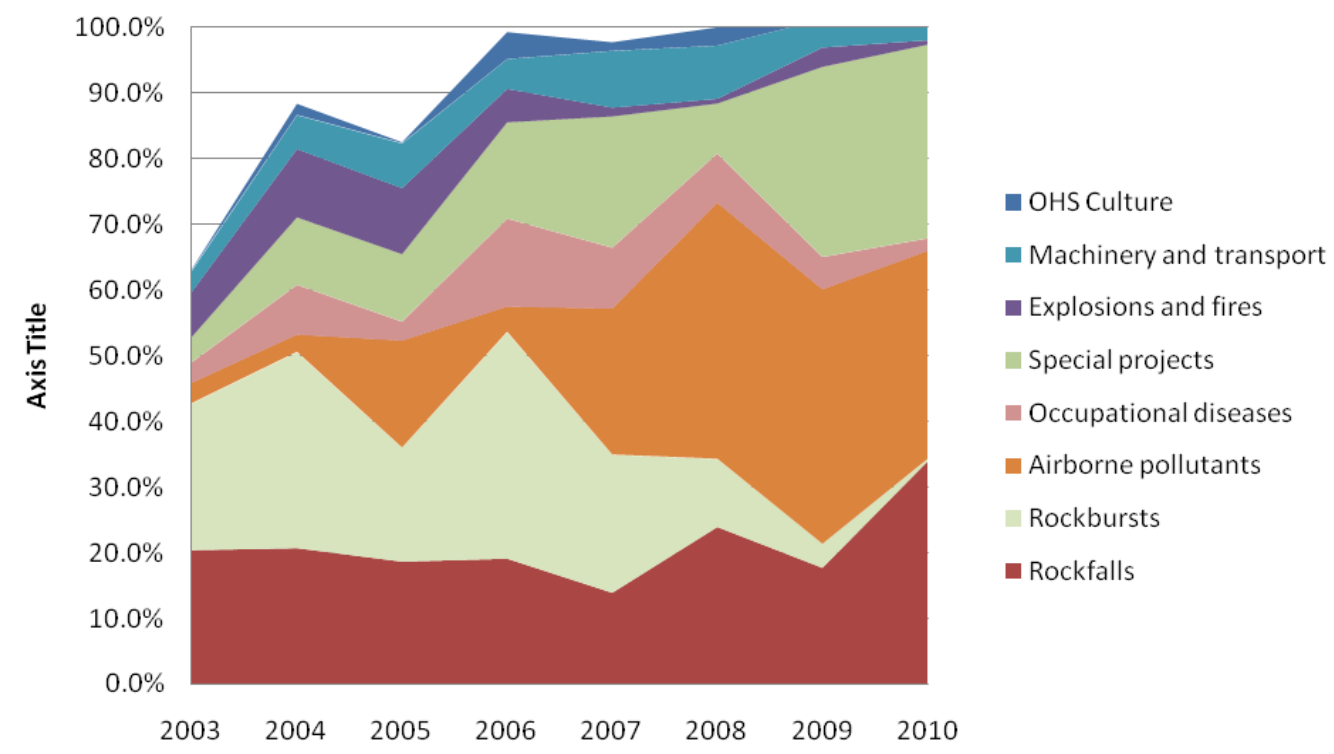

Figure 3 Change in distribution of MHSC research funding over time as a percentage of total MHSC research funding (derived from MHSC annual reports. The missing expenditure in 2003-2005 is due to projects not shown that were still in the pre-2003 classification system)

\section{5 The 2003 milestones}

The MHSC is mandated by the Mine Health and Safety Act to hold a Mine Health and Safety Summit at least every two years. At the 2003 summit, the tripartite stakeholders agreed to targets and milestones aimed at addressing the major health and safety concerns in the sector (Hermanus, 2007). The three targets and their associated milestones are set out here:

\section{Target: Zero fatalities and injuries}

Milestones:

- In the gold sector - to achieve by 2013 , safety performance levels at least equivalent to current international benchmarks for underground metalliferous mines (i.e. the average of the safety performance of mines in the US, Australia and Canada).

- In the platinum, coal and other sectors - to achieve by constant and continuous improvement, at least equivalent performance levels to current international benchmarks.

\section{Target: Eliminate silicosis}

Milestones:

- By December 2008, reduce $95 \%$ of exposures to below the occupational exposure limit for respirable crystalline silica of $0.1 \mathrm{mg} / \mathrm{m}^{3}$ (these results are individual readings and not average results).

- After December 2013, using present diagnostic techniques, cause no new cases of silicosis to occur among previously unexposed individuals (previously unexposed individuals are workers who would not have been exposed to silica prior to 2008, for example workers who are new entrants to the industry in 2008 or who have worked on mines or in occupations in which silica exposures were absent).

\section{Target: Eliminate noise-induced hearing loss (NIHL)}

Milestones: 
- After December 2008, hearing conservation programmes must ensure that deteriorations in hearing are no greater than $10 \%$ amongst occupationally exposed individuals.

- By December 2013, the total noise emitted by all equipment installed in any workplace must not exceed a sound pressure level of $110 \mathrm{~dB}(\mathrm{~A})$ at any location in that workplace.

It has been clear for some time that the milestones would not be easily achieved, see for example Edwards and Kritzinger (2011) and Figure 4. In 2007, Hermanus noted that "current trends in the available data indicate that the sector is not achieving the level of improvement needed to reach the milestones. However, significant resources have been galvanized, for example, to share information, identify helpful existing technologies, develop new technologies, support technology transfer, closely monitor trends, and understand the role of leadership. These activities bode well for the future" (Hermanus, 2007).

\section{South African mining fatality rate, 2003 to 2010}

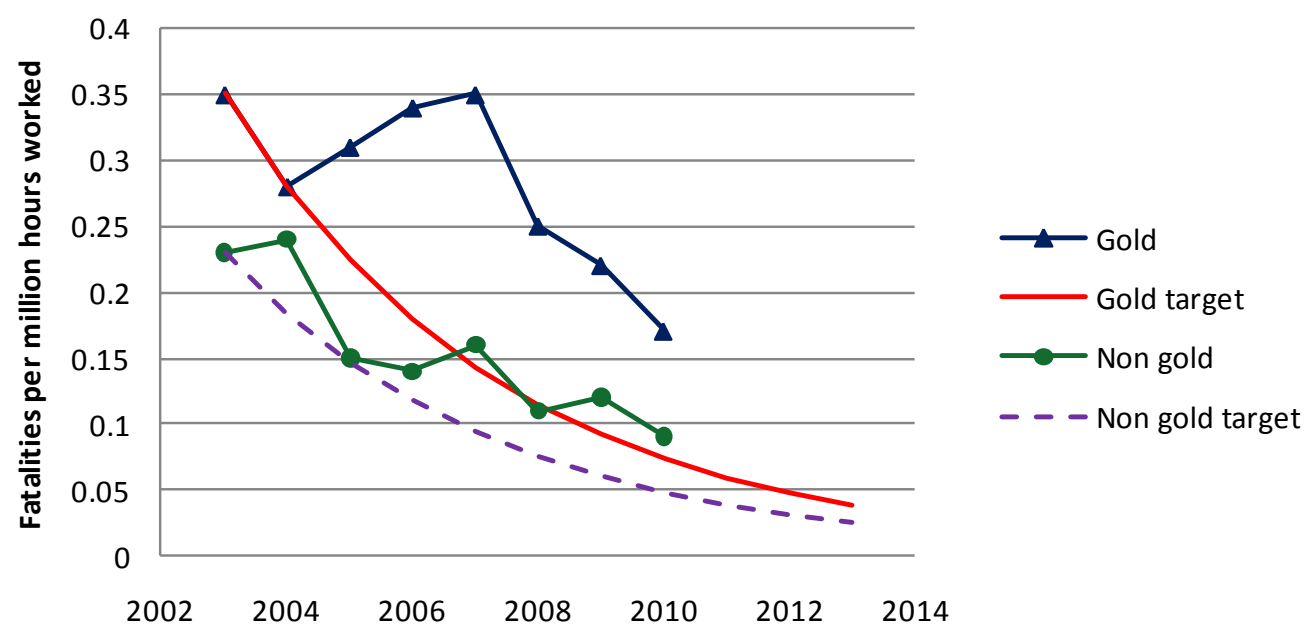

Figure 4 Industry performance compared to 2003 safety milestones (from van Zyl, 2009; including 2009 and 2010 data, pers. comm., Chamber of Mines)

\section{6 The MOSH initiative}

The elimination of accidents goes well beyond research, although research has a part to play. In order to ensure that the industry is applying best practice, the Mining Industry Occupational Safety and Health (MOSH) initiative was introduced.

In 2005 the CEO's of the major mining houses in South Africa met for a summit on mine safety, and established the MOSH task team (MOSH, 2011). The MOSH task team was established in response to the 2003 Industry Milestones, and has as its primary purpose the identification of best practice in the industry, and transfer of that best practice into other mines. It excludes research from its mandate. It has identified a number of best practices and is now working to roll them out across the industry, particularly into different environments.

\section{$3 \quad$ Mining research in the CSIR}

In 1993, COMRO was transferred to the CSIR and became the Division for Mining Technology, or Miningtek. The CSIR's rock mechanics division was also consolidated into Miningtek (Stacey et al., 2008). For the first few years of operation, the Chamber of Mines continued to support Miningtek through the mechanism of elective projects. In COMRO, a research budget was negotiated with the COM which would then levy its members to fund that research. One of the reasons that the COM ceased to fund research was the lack of agreement amongst its members around research priorities (Pogue, 2006). The elective funding mechanism allowed individual COM members to decide whether to participate in individual projects. However, there was a considerable overhead related to managing elective projects, and their popularity began to fall. 
Concurrently, with safety research having moved under the control of SIMRAC, the funding available to Miningtek from the industry started to decline. While the decline was not initially dramatic, it showed that Miningtek needed new sources of funding to maintain its operations.

The primary mechanism introduced was collaborative research programmes. The guiding principles of the collaborative programmes were (Durrheim, 2007):

- The research should be driven by industry needs.

- Collaboration between mining companies and research organisations was vigorously encouraged.

- Centres of tertiary learning were promoted.

- A joint funding model was adopted where industry funds were matched by the CSIR and the Technology and Human Resources for Industry Programme (THRIP).

Ultimately there were four collaborative programmes:

- DEEPMINE was established to create the technological and human resources platform for mining gold safely and profitably at depths of 3-5 km. It was a fixed life programme, established for four years, and ran from 1998-2002. It had a total budget of $R 66$ million at the time, equivalent to about R 120 million today (DEEPMINE, 2003).

- FutureMine was the successor to DEEPMINE (Durrheim, 2007). In an environment characterised by a volatile gold price, mature ore bodies and ageing infrastructure, the gold mining companies recognised that the major challenges facing the industry were the reduction of working costs (from US\$ 250/oz to US\$ 170/oz or lower) and the improvement of health and safety. Futuremine concentrated on implementing research results as quickly as possible.

- Coaltech 2020 was established in 1999, and had as its goal extending the life of the WitbankHighveld coal fields to 2020. It was initially established with a four year life, but offered sufficient value to its sponsors that the fixed period was renewed, and later made open ended. It is still in operation today as the Coaltech Research Association (Coaltech, 2011) and funded research to a value of R 7.8 million in 2008/2009.

- PlatMine was established in 2003 to undertake research supporting mechanisation in the platinum industry. Unlike the previous collaboratives, PlatMine never attempted to obtain THRIP funding, and was funded $50 \%$ by industry and $50 \%$ by the CSIR. PlatMine is still in operation, though with a limited industry budget of just R 3 million per annum.

In about 2005, following a change in policy, the CSIR stopped matching industry funding in the collaborative programmes. At about the same time, the rules of THRIP started changing, and it is now a relatively small contributor to Coaltech. While funding levels were initially good, they did not keep up with inflation, and have left the CSIR seeking other avenues of funding if it is to maintain significant technical competency.

In 2005, the CSIR celebrated its 60th anniversary, and initiated a period of organisational change. It acknowledged that over the previous 20 years, its focus had been on financial survival and that it had developed good business disciplines, but that its underlying science base had been weakened. The return of emphasis to science was encapsulated in the reorganisation known as Beyond 60, which had a number of repercussions for mining:

- Miningtek was merged with the division of Environmental Technology at the CSIR to form a new operating unit known as Natural Resources and the Environment (NRE). There was hope that the similarities between mineral resources and other natural resources such as water and forestry would lead to organisational synergies and improved effectiveness.

- The rock testing laboratory became part of the Built Environment unit. 
- Services, such as rope testing, fires and explosions testing and support testing were moved into the CSIR's commercial arm, which became known as Consulting and Analytical Services (CAS).

The decline in the mining research capacity at CSIR is clear from Figure 5. It had become clear that while mining and other natural resources share similarities, mining research did not fit well into the management system of a unit focussed on the environment. In an attempt to improve the visibility of the mining to industry, and to reverse the decline in capacity, mining was separated from NRE in September 2009 to become the autonomous Centre for Mining Innovation (CMI).

$\mathrm{CMI}$ has since been operating as a separate entity, and has managed to slow the decline in researcher numbers. With the initiatives described in Section 5, the intent is to grow the unit back to the point where it can again undertake sustainable world class research and have a significant impact on South African industry, in line with the CSIR mandate.

CSIR mining staff complement

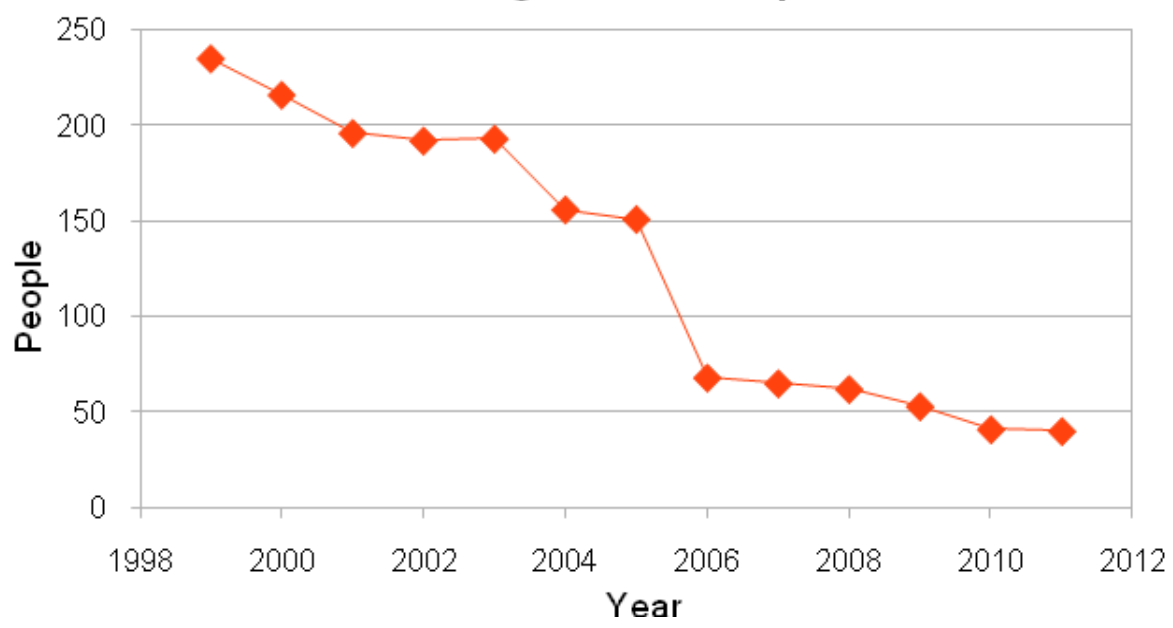

Figure 5 Staff compliment at CSIR: in Miningtek (1999-2005), Mining Competence at NRE (2006-2009), Centre for Mining Innovation (2010-2011)

\section{$4 \quad$ Current challenges}

\section{1 Health and safety}

While the accident and fatality rates in South Africa are definitely coming down (Figure 6, left), in 2010, 128 miners lost their lives, which is still well above the international benchmark, and unacceptably high. The sources of accidents show that the single biggest cause of fatalities remains falls of ground. While there is much that can be done to prevent fall of ground accidents through good practice, good practice alone cannot eliminate the risks that we don't currently understand. In many areas, there are substantial requirements for research to eliminate accidents and fatalities. While not shown here, the requirement for research in health is, if anything, greater. 


\section{South African mining fatality record}

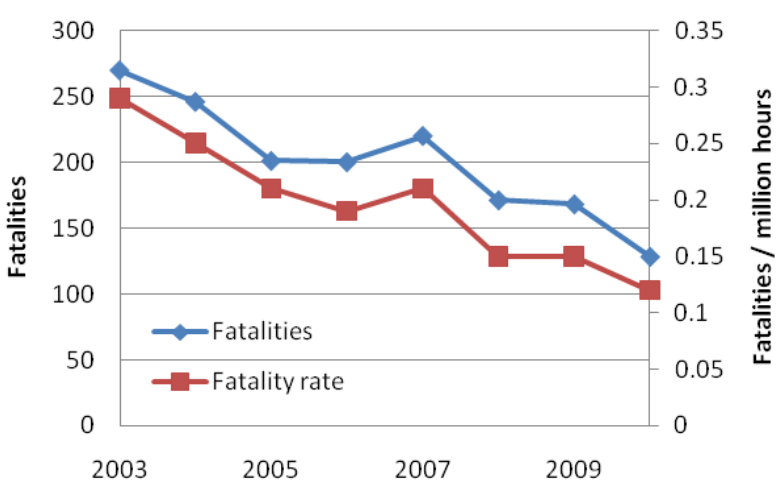

\section{Fatalities by type}

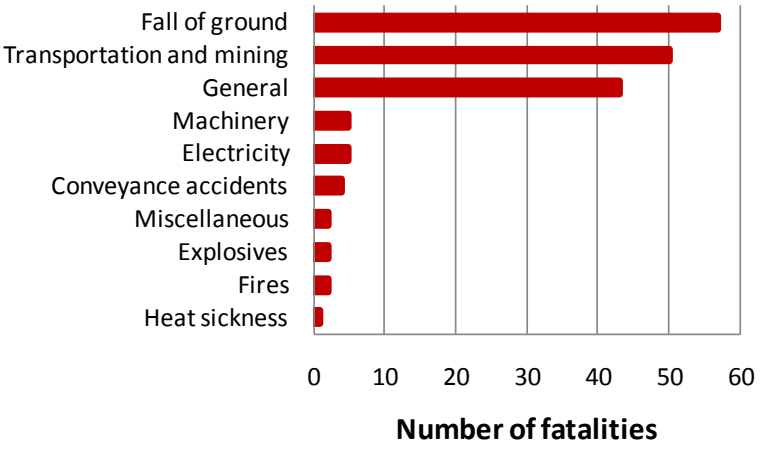

Figure 6 Fatality record (left) and categorisation of fatalities in 2008 ( $r$ ight)

\section{2 The economic imperative}

Mining is important to South Africa. In 2009, mining contributed about $19 \%$ of GDP (8.8\% directly); over $50 \%$ of merchandise exports; and approximately one million jobs of which about 500,000 indirectly (COM, 2010). However, the industry is under pressure as orebodies go deeper and become more difficult to mine. As an example, gold production and gold grade have both been declining over the last 40 years (Figure 7), and only a change in technology will reverse the trend in production.

\section{South African gold production, 1910 to 2010}

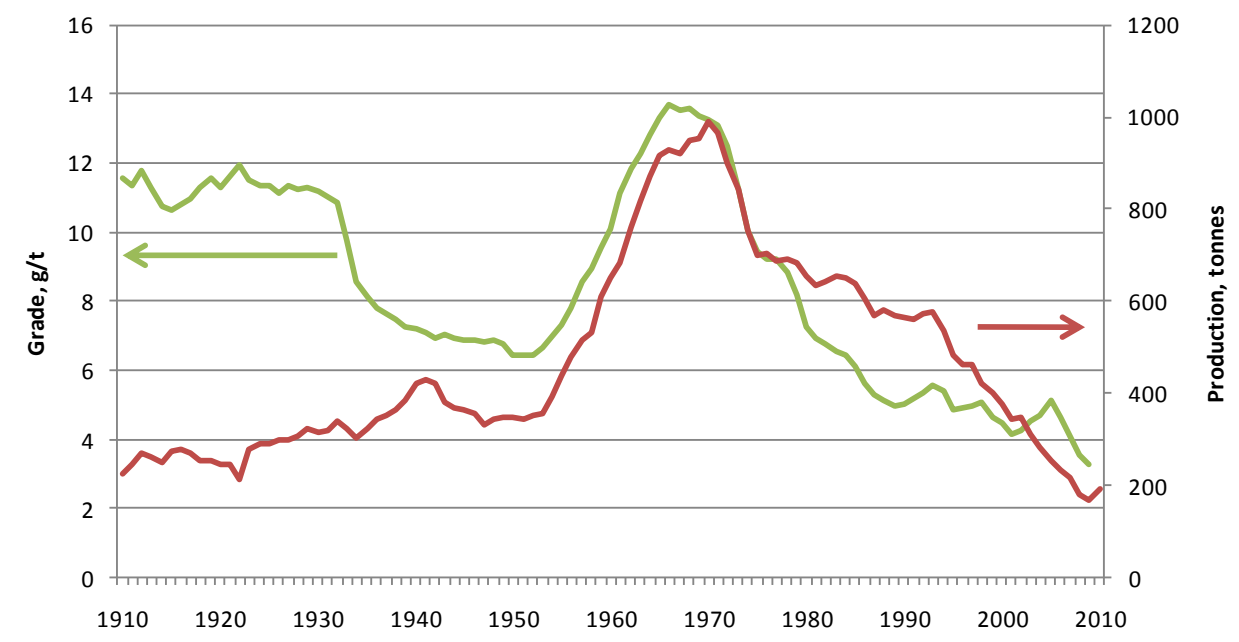

Figure 7 South African gold production and grade, 1910-2010

\section{3 Technology is important}

Historically, research has overcome a number of issues that threatened to curtail mining in South Africa. Among others:

- Research into heat stress and heat tolerance screening has almost eliminated heat stroke as a cause of fatalities.

- Deep level gold mining was able to manage the challenge of increasing seismicity through the introduction of hydraulic props, new mine designs and backfill.

- Preconditioning has greatly reduced the danger from face bursting.

- Pillar design formulas developed by Salamòn and others (Van der Merwe, 2006) greatly reduced pillar failure on coal mines. 
While the fatality rate remains unacceptably high, single events with large numbers of fatalities are much less common than previously, due to changes in practice driven by research findings.

Mining is facing a number of emerging challenges, particularly to its social license to mine, and is subject to a critical shortage of skilled personnel. Several large mining company CEOs have recently noted that technology provides an answer both to improving safety and to overcoming the challenges caused by a lack of technical skills.

\section{4 Government policy}

The Department of Mineral Resources (DMR) has no published research policy. It is involved in the Mining Industry Growth, Development and Employment Task Team (MIGDETT) that was established in December 2008 as collaboration between the DMR, business and labour to help the industry manage the negative effects of the global economic crisis and save jobs, and to position the industry for growth and transformation in the medium to long term. In June 2010, the parties involved in MIGDETT announced a 13 Commitment accord to grow and transform the industry. Commitment 3 mentions the importance of innovation through research and technology development, and commits to, among others, resuscitating a research and development culture in the mining industry. While established with much publicity, progress from MIGDETT has been slow and there has been very little concrete development coming out of it to date.

The MIGDETT process is credited with returning mining to the national priority list in the "New Growth Path" announced by Minister Ebrahim Patel.

In the 2002 Department of Science and Technology document on South Africa's research and development strategy, mining is discussed in some detail (DST, 2002). Later, that focus disappeared: mining is not mentioned in the five grand challenges or the 10 year plan of 2008 (DST, 2008). The previous minister, $\mathrm{Dr}$ Mosibudi Mangena, spoke about the importance of mining, and admitted that it had been neglected by his department, when he addressed the CSIR in 2008. The current minister, Ms Naledi Pandor has not expressed a view yet.

Mining is not seen as a key area for investment by the Department of Trade and Industry. It was not mentioned in the first or second Industrial Policy Action Plan (IPAP). Mining equipment is part of the second IPAP capital goods and automotive sectors. There is discussion within government to ensure that the third IPAP will incorporate support for mining.

\section{$5 \quad$ The future}

Given that there is clearly a need for mining research in South Africa, how can the capacity and capability be re-built?

\section{1 Centre of Excellence}

The most important route to rebuilding research capacity is through the Centre of Excellence mandated at the 2008 Industry Safety Summit. The key element of the Centre's design needs to be the recognition that there are critical research areas in which capacity must be maintained in South Africa by the Centre. The CSIR suggests a model that acknowledges three groups of competencies required to meet the needs of the industry and the state for research in rock engineering, human factors including appropriate incentive systems, mining, engineering and occupational health and hygiene (MHSC, 2010):

- Where appropriate the Centre maintains its own competencies.

- Core competencies are supported at other appropriate institutions.

- Some required competencies can be obtained from other disciplines, and therefore do not require long-term support by the Centre. 
The CSIR suggests that the Centre follows the guidelines laid down by the Leon Commission for its research management (Leon et al., 1995) and that it be organised in a manner similar to that suggested by O'Keefe and Head (2011) for CSIRO's flagship programmes. In particular, it is important that the design of the Centre drives its activities towards the creation of impact. A proposed path to impact lifecycle is illustrated in Figure 8.

The circular flow diagram in the inside of the model illustrates the typical activities involved in research, but extends well beyond the output of the research, to include the adoption path, reduction to practice and delivery. The whole process is defined by the need to have impact. The circles around the flow diagram are at successively higher levels of organisation:

- The innermost circle classifies the activities in the flow diagram.

- The middle circle defines the activities required from the Centre of Excellence management.

- The outermost circle stresses the importance of stakeholder engagement, and is the place where tripartite input to the process would be implemented.

A separate logic model should be applied to each group of projects that meets a single national goal and that is implemented through a single adoption path.

Apart from the research programme, a Centre of Excellence would also play a role in undertaking statutory testing for the mining industry. The current funding model is for mine sites to pay for testing services. As an alternative, license fees charged by DMR could include the cost of testing, with DMR then funding testing facilities within the Centre of Excellence. This alternative would provide longer term commitment to the testing facility, allowing it to improve the quality of its service delivery to all stakeholders.

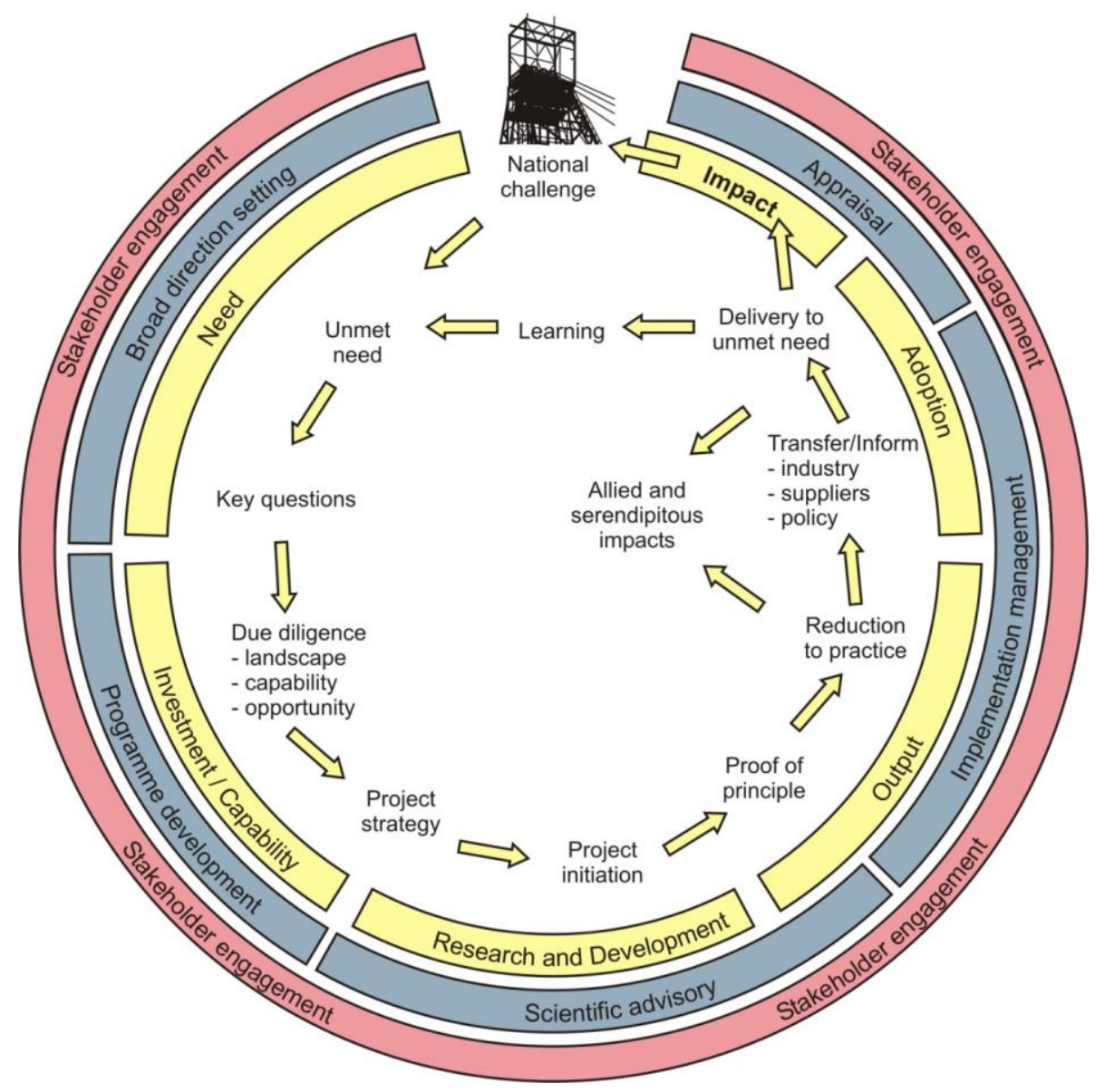

Figure 8 A path to impact Iifecycle (after 0' Keefe and Head, 2011) 


\section{2 The CSIR mining research impact area}

At present, with internal funding of more than R 30 million being directed at mining related research in 2011, the CSIR is the country's largest funder of mining-related research and development. It aims to build on this by consolidating its activities and working with partners.

In 2010, following a review of its activities, the CSIR recognised the need to ensure that its research has an impact in society. Six research impact areas (RIAs) were defined as central to the new strategy: health, environment, defence, energy, built environment and industry; and the industry RIA was subdivided into advanced manufacturing and mining. Each RIA is intended to ensure that all relevant research across the CSIR is coordinated under one umbrella. The mining RIA strategy is expected to be finalised in the second half of 2011.

Current thinking is summarised in Figure 9, and takes the form of a logic model (Kellogg, 2004). The inputs to the process are an analysis of industry requirements and the skills currently available within CSIR. Four focus areas have been selected for the CSIR: health and safety; decision support systems; new mining methods; and smart systems.
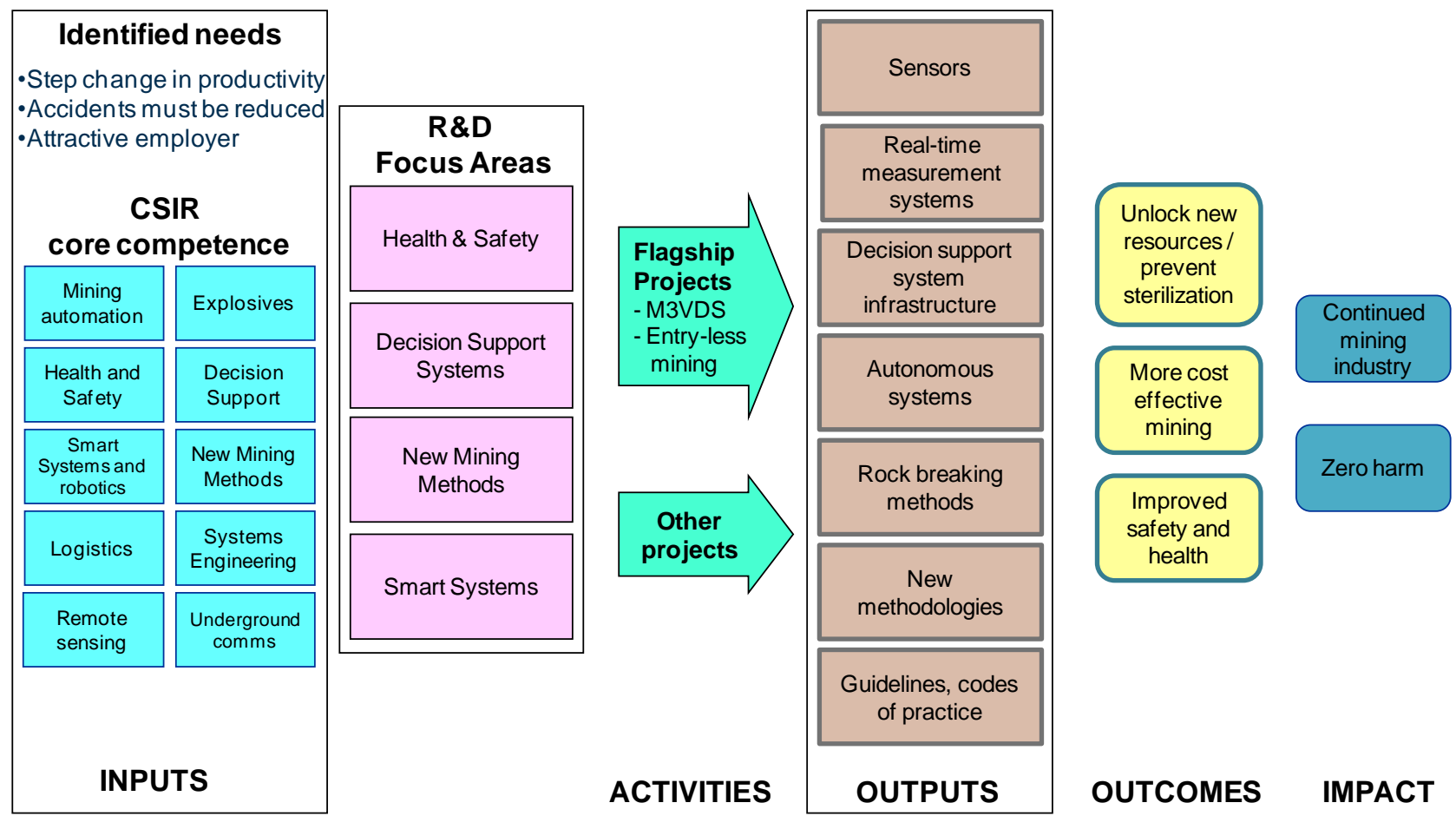

Figure 9 The CSIR Mining Research Impact Area logic model

Projects will be undertaken in a number of fields, both existing and new contract research, and the socalled flagships. Two flagships are proposed:

- Mine measurement, modelling, visualisation and decision support (M3VDS): the vision is of a control room where the current state of the mine is available, and where modelling can be easily undertaken to make "what if" decisions about the impact of interventions. The model would integrate all areas of the operation, including geology, rock mechanics, process scheduling, ventilation and occupation health and safety.

- Entry-less mining: about half of all rock related fatalities in South Africa occur in the stope, with $89 \%$ of those occurring within $2.5 \mathrm{~m}$ of the working face (Roberts et al., 2001). An obvious route to improve safety is to remove people from the face. The flagship will concentrate on developing technology to achieve that goal, in areas such as navigation, rock breaking and technical support for equipment operating in areas where people are prohibited. 
A third obvious flagship would be health and safety, but at a national level this will fall under the Centre of Excellence as discussed in the previous section.

Outputs can take many forms, but should lead to one of three outcomes: new resources becoming viable; more cost effective mining; and improved health and safety. These outcomes will in turn lead to the continued development of the industry, and to zero harm to workers.

\section{3 Other research initiatives}

Anglogold Ashanti has embarked on a technology innovation consortium (TIC) approach to changing the way that it mines gold in South Africa (AGA, 2011). The TIC is a collection of suppliers and research providers, working with Anglogold Ashanti to develop equipment and techniques to allow the deeper orebodies of the Witwatersrand to be mined safely and economically. The prize is enormous but the challenge is also large.

The Department of Science and Technology has been investigating the need for mining research in South Africa and Africa and how it can become involved in coordination through their Framework for Mining Geosciences Research and Development in Africa initiative. This shows that the comments made by the previous minister of Science and Technology, Minister Mosibudi Mangeni, mentioned in Section 4.4 previously, have resulted in changes in policy within the Department.

On a scientific level, the CSIR, the Council for Geoscience and the University of the Witwatersrand are working with Japanese partners as part of the Japan-South Africa Collaborative Science and Technology Research Partnership for Sustainable Development (SATREPS) project "Observational studies to mitigate seismic risks in mines" (Durrheim et al., 2009). This project recognises the unique opportunities offered by South African mines to place instrumentation very close to active faults (within $200 \mathrm{~m}$ ), so that the activity in the near field of an earthquake can be closely monitored. The CSIR contribution to the project is in trying to understand the impact of seismic events on nearby excavations, leading ultimately to improved design of such excavations to allow them to survive seismic events. The project is particularly important in providing the opportunity to develop a new generation of mine seismology researchers in South Africa.

\section{Conclusion}

South African mining research has been decaying for the last 20 years, but stakeholders are slowly realising the impact in terms of the unavailability of research skills, and also on the knock-on effect of a more general lack of high level technical skills to local industry. This realisation is prompting a number of attempts to rebuild mining research capabilities in South Africa. It remains to be seen if this is too little, too late, but the signs are promising that South Africa will start to support its researchers again in the way that other major mining countries started to do over the last decade.

\section{Acknow l edgements}

I thank my colleagues and referees for their constructive criticism of this paper, and acknowledge the many researchers who have helped to make the South African mining what it is today.

\section{References}

AGA (2011) Anglogold Ashanti. Anglogold Ashanti Technology Innovation Consortium, viewed 3 June 2011, http://www.aga-tic.com/agatic/index.jsp.

Coaltech (2011) viewed 3 June 2011, http://www.coaltech.co.za/.

COM (2010) Chamber of Mines of South Africa. Facts and Figures, 2009, Chamber of Mines of South Africa, Johannesburg. DEEPMINE (2003) DEEPMINE 1998-2002, DEEPMINE, Johannesburg.

DST (2002) Department of Science and Technology. South Africa's National Research and Development Strategy, The Government of the Republic of South Africa, Pretoria.

DST (2008) Department of Science and Technology. The Ten-Year Plan for Science and Technology, The Government of the Republic of South Africa, Pretoria. 
Durrheim, R. (2007) The DeepMine and FutureMine Research Programmes - Knowledge and Technology for Deep Gold Mining in South Africa, In Challenges in Deep and High Stress Mining, Y. Potvin, J. Hadjigeorgiou and D. Stacey (eds), Australian Centre for Geomechanics, Perth, Chapter 15, pp. 133-141.

Durrheim, R.J., Ogasawara, H., Nakatani, M., Yabe, Y., Milev, A., Cichowicz, A., Kawakata, H. and Moriya, H. (2009) Observational study to mitigate seismic risks in mines: a new Japanese-South African collaborative project, in 11th South African Geophysical Association Biennial Technical Meeting and Exhibition, Swaziland, 16-18 September 2009, pp. 73-79.

Edwards, A. and Kritzinger, D. (2011) The 2008 NIHL Milestone: what can we learn? Presented at Mine Ventilation Society of SA 2011 conference, 12-13 May, Johannesburg, South Africa.

Hermanus, M.A. (2007) Occupational health and safety in mining-status, new developments, and concerns, Journal of the South African Institute of Mining and Metallurgy, August, Vol. 107, pp. 531-538.

Kellogg (2004) Logic model development guide, W.K. Kellogg Foundation, Michigan, USA.

Leon, R.N., Salamòn, M.D.G., Davies, A.W. and Davies, J.C.A. (1995) Report of the Commission of Inquiry into Safety and Health in the Mining Industry, Department of Mineral Resources, South Africa.

Looch, K. (2009) Leon Commission of Inquiry into Safety and Health in the Mining Industry (Report 1995), viewed 3 June 2011, http://www.klasslooch.com/leon_commission_of_inquiry.htm

MHSC (2010) Mine Health and Safety Council Annual Report 2009/2010, Mine Health and Safety Council, Woodmead, South Africa, p. 31.

MOSH (2011) Mining Industry Occupational Safety and Health Home page, viewed 3 June 2011, http://www.mosh.org.za/.

O'Keefe, C.M. and Head, R.J. (2011) Application of logic models in a large scientific research program, Evaluation and Project Planning, Vol. 34, pp. 174-184.

Pogue, T.E. (2006) Lessons for the future: the origins and legacy of COMRO's hydraulic technology programme, Journal of the South African Institute of Mining and Metallurgy, August, Vol. 106, pp. 515-525.

Roberts, M.K.C., Daehnke, A. and Jaku, E.P. (2001) Rock-related fatality trends in the South African gold mining industry, Journal of the South African Institute of Mining and Metallurgy, October, pp. 353-358.

Rymon-Lipinski, W.K. and Adams, D.J. (2003) Rock engineering, crucial for sustainable development in the South African mining industry, 30th International Conference of Safety in Mines Research Institutes, South African Institute of Mining and Metallurgy, pp. 165-176.

Stacey, T.R., Hadjigeorgiou, J. and Potvin, Y. (2008) Technical skills - a major strategic issue, Journal of the South African Institute of Mining and Metallurgy, December, Vol. 108, pp. 775-782.

Van der Merwe, J.N. (2006). Beyond Coalbrook: Critical Review of Coal Strata Control Developments in South Africa, 25th International Conference on Ground Control in Mining (ICGCM), pp. 335-346.

van Zyl, A. (2009) MOSH Falls of Ground Adoption Team, in Hard Rock Safe Safety Conference 2009, The Southern African Institute of Mining and Metallurgy, Johannesburg, South Africa.

World Gold Council (2011) Monthly gold price data, viewed 3 June 2011, http://www.gold.org/download/value/stats/statistics /xls/Prices_in_various_currencies_from_1998.xls. 
